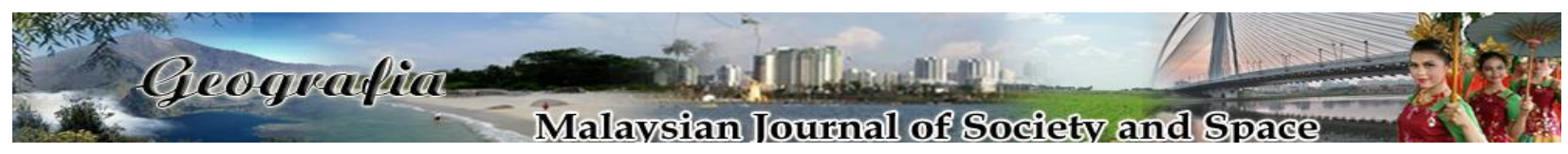

\title{
Kesenian Randai sebagai manifestasi budaya masyarakat Perpatih di Negeri Sembilan
}

\author{
Nor Atikah Azmi, Zubir Idris, Ab. Samad Kechot \\ Pusat Kajian Bahasa, Kesusasteraan dan Kebudayaan Melayu, Fakulti Sains Sosial dan Kemanusiaan, \\ Universiti Kebangsaan Malaysia.
}

Correspondence: Zubir Idris (email: zidris@ukm.my)

Received: 02 March 2021; Accepted: 07 May 2021; Published: 29 May 2021

\begin{abstract}
Abstrak
Kajian ini mengetengahkan kesenian Randai sebagai salah satu kesenian rakyat yang terdapat di Negeri Sembilan. Sungguhpun kesenian ini mempunyai ikatan yang rapat dengan tradisi dan kesenian Minangkabau, kajian lebih menumpukan kesenian Randai yang sudah berasimilasi dengan kebudayaan Negeri Sembilan. Kajian ini menggunakan pendekatan kualitatif. Kesenian Randai yang menjadi tumpuan ialah di mukim Lenggeng, Seremban, Negeri Sembilan atas faktor majoriti masyarakat Perpatih yang masih boleh bertutur dalam bahasa Minang selain daripada kepakaran ahli dalam kesenian yang masih aktif mempersembahkan kesenian Randai. Persoalan kajian yang ingin dirungkai ialah berkenaan elemen budaya yang terdapat dalam lirik-lirik lagu dalam kesenian Randai. Elemen-elemen budaya yang dirungkai ialah berkaitan dengan agama dan kepercayaan. Untuk merungkai elemen-elemen budaya dalam lagu, pengkaji mengguna pakai konsep etnomuzikologi yang melihat hubungan muzik terhadap aspek-aspek kebudayaan dalam hasil seni sesebuah masyarakat. Kompleksiti berkenaan aspek budaya sememangnya tidak asing dalam apa jua hasil kesenian rakyat, namun ia perlu diinterpretasikan untuk kefahaman yang lebih baik terutamanya kepada mereka yang berada di luar ruang lingkup tradisi Adat Perpatih.
\end{abstract}

Kata Kunci: Adat Perpatih, agama dan kepercayaan, budaya, etnomuzikologi, kesenian Randai, Minangkabau 


\title{
Randai art as a cultural manifestation of the Perpatih community in Negeri Sembilan
}

\begin{abstract}
This study explores the art of Randai as a one of the folk arts in Negeri Sembilan. Although Randai in Negeri Sembilan is closely related to the Minangkabau tradition, but this study focuses on Randai that assimilated with culture on Negeri Sembilan. The art of randai that being focusing is in mukim Lenggeng, Seremban due to the ability of its members to speak in Minang and the expertise among members which are still active in performing the art of Randai. This study would like to unraveal the cultural elements found in lyricals of Randai art. The cultural elements studied are religion and belief. The approach used is the concept of ethnomusicology which sees the relationship of music to the cultural aspects in the artwork of a society. Complexity regarding cultural aspects is not unfamiliar in any artistic work of the people, but it needs to interpreted for a better understanding, especially to those who are outside the scope of Perpatih Customary traditions.
\end{abstract}

Keywords: Perpatih Customs, religion and belief, culture, ethnomusicology. Randai art, Minangkabau.

\section{Pengenalan}

Negeri Sembilan terletak di wilayah pantai barat Tanah Melayu yang bersempadan dengan Negeri Selangor di bahagian barat laut, Pahang di bahagian utara, Melaka di selatan dan Johor di tenggara dan selat Melaka di bahagian baratnya. Negeri Sembilan kompleks bukan hanya dari sudut adatnya tetapi juga geografinya. Sebagaimana dibayangkan oleh namanya, Negeri Sembilan merupakan gabungan sembilan buah negeri menjadi sebuah kesatuan politik. Bagaimanapun masih belum jelas negeri-negeri mana yang pada asalnya bergabung untuk melahirkan Negeri Sembilan. Menurut R.O. Winstedt (dalam Khoo Kay Kim, 1990), sehingga tahun 1682 'Negeri Sembilan' tidak pernah disebutkan termasuk Klang, Sungai Ujong, Naning, Rembau, Jelai, Ulu Pahang, Jelebu, Johol dan Segamat, kawasan-kawasan ini merupakan kawasan yang didiami oleh orang Minangkabau. Klang, Sungai Ujong, Naning dan Rembau memang telah wujud sejak zaman Portugis di Melaka, sebagaimana juga Johol dan Jempol. Tulisan-tulisan orang Portugis pada abad ke-16 menunjukkan bahawa ramai orang Minangkabau dari Sumatera telah menetap di kawasankawasan tersebut. Menurut Godinho d'Eredia (dalam Khoo Kay Kim) penduduk Naning pada masa itu terdiri daripada orang Minangkabau yang kebanyakan daripada mereka menjalankan perniagaan di kawasan-kawasan tersebut.

Pada peringkat awal, Negeri Sembilan merupakan gabungan sembilan buah luak atau negeri dan kini dianggotai oleh tujuh buah daerah iaitu Rembau, Tampin, Kuala Pilah, Jelebu, Seremban (dahulunya Sungai Ujong), Port Dickson dan Jempol. Negeri Sembilan lebih dikenali sebagai negeri adat kerana Adat Perpatih yang dibawa oleh imigran Minangkabau (Nelmawarni Bungo, Nordin Hussin, 2011). Mereka merupakan kelompok awal yang meneroka tanah di negeri tersebut dan Adat Perpatih telah menjadi pegangan yang kukuh dalam kalangan masyarakatnya. Kedatangan masyarakat Minangkabau telah membuka lembaran baru dalam sejarah Negeri 
Sembilan secara umumnya. Terdapat dua kumpulan penghijrah Minangkabau yang datang ke Negeri Sembilan. Penghijrah Minangkabau yang datang dari daerah pedalaman Sumatera mengamalkan Adat Perpatih sementara kumpulan kedua datang dari daerah persisiran Sumatera dan mengamalkan Adat Temenggung. Sebagai masyarakat yang mengamalkan Adat Perpatih, kewibawaan politik Negeri Sembilan bermula dari bawah iaitu melibatkan 'anak buah'. Tidak seperti di Minangkabau, jumlah suku hanya empat jika dibandingkan dengan jumlah suku di Negeri Sembilan iaitu suku Biduanda atau Waris, Batu Hampar, Paya Kumboh, Mungkal, Tiga Nenek, Seri Melenggang, Seri Lemak, Batu Belang, Tanah Datar, Anak Aceh, Anak Melaka dan Tiga Batu.

Terdapat juga etnik-etnik lain yang menetap di Negeri Sembilan seperti orang Melayu. Mereka menempati daerah di sekitar lembah Sungai Linggi, Sungai Ujong dan Rembau. Memandangkan ketiga-tiga daerah ini terletak berdekatan dengan Melaka, dapat dikatakan orang Melayu yang menduduki kawasan tersebut merupakan penduduk kerajaan Melayu Melaka yang melarikan diri setelah Melaka ditawan oleh Portugis pada tahun 1511. Kebanyakan orang Melayu Melaka berasal dari Palembang dan Riau yang berhijrah ke Melaka sewaktu zaman keagungan Kesultanan Melayu Melaka 1403-1511. Terdapat juga orang-orang Rawa yang kemungkinan besar datang dari Sumatera dan berpindah ke Selangor dan Negeri Sembilan (Hamzah Jusoh, Habibah Ahmad, Amirah Buang, \& Ari Kurnia 2011).

\section{Penghijrahan migrasi Minangkabau ke Negeri Sembilan}

Pelbagai pendapat telah diutarakan oleh para sejarawan mengenai tarikh kedatangan masyarakat Minangkabau ke Negeri Sembilan. Seorang sejarawan iaitu T.J. Newbold (dlm. Mohd Dahlan Mansoer, 1990) menyatakan bahawa penghijrahan orang-orang Minangkabau ke Tanah Melayu berlaku dalam abad ke-12. Kumpulan pertama tersebut diketuai oleh Tu Pattair yang mula-mula sampai ke Melaka, seterusnya mudik ke Sungai Melaka dan tiba di suatu tempat bernama Tabo (Tabuh Naning). Beliau seterusnya berkahwin dengan seorang gadis Jakun serta menetap di situ sehingga terbentuk sebuah perkampungan Minangkabau yang pertama di Tanah Melayu. Manakala R.J. Wilkinson (dlm. Mohd Dahlan Mansoer, 1990) berpendapat bahawa penghijrahan masyarakat Minangkabau ke Tanah Melayu berlaku tidak berapa lama selepas kejatuhan Kesultanan Melayu Melaka ke tangan Portugis pada tahun 1511. Buyong Adil (dlm. Abdul Samad Idris, 1974) menyatakan kedatangan orang Minangkabau ke Negeri Sembilan berlaku sekitar kurun ke-15. Hal ini dinyatakan oleh beliau berdasarkan kewujudan sebuah makam di Sungai Udang, Linggi yang dikatakan makam seorang yang bernama Sheikh Ahmad. Hal ini membawa kepada persamaan pada batu nisan yang menyerupai batu bersurat di Batu Sangkar dan Pagar Ruyong di Sumatera. Dalam konteks ini, Sheikh Ahmad dipercayai individu yang berasal dari Minangkabau yang telah merintis jalan untuk kedatangan orang-orang Minangkabau ke Negeri Sembilan khasnya dan Semenanjung Tanah Melayu amnya.

Penghijrahan orang-orang Minangkabau ke Negeri Sembilan terutama di daerah-daerah pedalaman seperti Jelebu, Rembau, Kuala Pilah, Johol dan Sri Menanti membawa kepada perkahwinan campur antara masyarakat tempatan dengan orang Minangkabau. Hal ini telah membawa kepada perubahan dalam sistem sosiopolitik masyarakat tempatan. Amalan sistem matrilineal dalam kalangan masyarakat Minangkabau ialah faktor utama yang membawa kepada penghijrahan mereka ke daerah-daerah lain. Tambahnya lagi, penghijrahan ini bertujuan untuk mencari kekayaan, pengetahuan dan pengalaman serta mempunyai hasrat pulang ke tanah air 
mereka setelah matlamat mereka dicapai (Midawati, \& Amirah Buang, 2015). Di samping itu, terdapat juga beberapa faktor lain yang mendorong kemasukan orang Minangkabau ke Negeri Sembilan. Antaranya sifat semula jadi mereka yang suka merantau, berlakunya perang saudara yang memecahkan Alam Minangkabau (abad ke-17) dan juga suasana politik dan keadaan ekonomi di daerah seberang Selat Melaka yang lebih baik daripada negeri mereka. Penghijrahan ini juga turut menyaksikan berlakunya asimilasi budaya antara penduduk asal di Negeri Sembilan dengan budaya yang dibawa masuk daripada Alam Minangkabau khasnya dalam kesenian rakyat seperti seni lagu, seni rupa, seni tampak dan seni bina.

\section{Kesenian Randai di Negeri Sembilan}

Randai adalah salah satu kesenian tradisional yang berasal daripada bumi Minangkabau di Sumatera Barat. Kesenian ini dipercayai wujud sekitar tahun 1932 di Labuah Basilang Kabuputen Lima Puluh Kota. Kesenian Randai juga dikenali sebagai persembahan kaba yang mendapat pengaruh daripada teater komedi bangsawan Melayu, Minang. Masyarakat di Minangkabau mempersembahkan kesenian Randai dalam upacara adat dan acara-acara seperti pesta perkahwinan, hiburan kepada pelancong dan pesta-pesta rakyat yang lain (Arifini Netrirosa, 2010). Kesenian Randai wujud daripada pelbagai unsur kesenian rakyat Minangkabau. Menurut Mursal Esten (dlm. Arifini Netrirosa, 2010), menjelaskan kesenian Randai merupakan kesenian rakyat Minangkabau yang terikat dengan unsur-unsur penting seperti 'kaba' (cerita), 'vokal' (gurindam), 'gerak tari' (gelombang) dan dialog antara para pelakon.

Kesenian Randai yang dibawa masuk oleh migrasi Minang ke Negeri Sembilan telah mengalami pelbagai perubahan terutamanya daripada segi elemen bahasa dan cara persembahan. Perubahan ini sedikit sebanyak berlaku atas sebab penyesuaian mengikut persekitaran masyarakat ketika itu. Namun masih terdapat beberapa ciri yang sama antara kesenian Randai di Negeri Sembilan dengan Randai di Minangkabau. Ciri yang membawa kesamaan tersebut ialah unsur essential dan unsur pendukung. Unsur essential terdiri daripada cerita, gurindam, gelombang, dialog dan lakonan. Unsur ini dianggap essential kerana ia menggerakkan sesebuah persembahan Randai. Sekiranya salah satu unsur ini tidak ada, maka Randai tidak dapat dipersembahkan. Unsur pendukung pula terdiri daripada kostum, tatarias dan muzik. Kedua-dua unsur ini saling berkait untuk menyempurnakan persembahan Randai tidak kira Randai di Negeri Sembilan mahupun di Minangkabau (Abd. Samad Kechot, 2009).

Kesenian Randai dikatakan terdapat di beberapa daerah Negeri Sembilan sahaja seperti di Lenggeng, Jelebu, Kuala Pilah dan Mantin. Kesenian Randai juga dikatakan pernah wujud di Klang tempat wujudnya penempatan masyarakat Minangkabau suatu masa dahulu. Randai dalam maksud bahasa Minangkabau membawa maksud 'mengarung' atau melingkari'. Menurut Encik Buyong Adam (dlm Azizah Mohd Nor, 1979), Randai membawa pengertian yang mendalam sekali dalam masyarakat Minangkabau. Kesenian ini membawa tujuan menyusun sahabat handai untuk sepakat bergotong-royong membantu sahabat atau saudara yang ditimpa atau dalam kesusahan. Oleh sebab itu, kesenian Randai dipersembahkan dalam bentuk bulatan sesuai dengan kata pepatah 'bulat air kerana pembetung, bulat manusia kerana muafakat'. Pengertian kata pepatah tersebut menjelaskan tentang hal sepakat dan sebulat hati yang melambangkan perpaduan dalam masyarakat Melayu khususnya masyarakat Minangkabau.

Kesenian Randai dikatakan bermula dengan satu peristiwa malang yang menimpa seorang penduduk di sebuah kampung di kawasan penempatan masyarakat Minangkabau. Si Malang itu telah kehilangan barang kesayangannya. Lantaran daripada peristiwa itu, Si Malang itu tidak lalu 
makan dan hidup menderita. Penduduk-penduduk kampung di sekitarnya simpati dengan keadaan yang menimpa lelaki berkenaan, lalu sepakat untuk bersama-sama mencari barang yang hilang itu. Mereka berkumpul di kawasan barang yang dikatakan hilang dengan membuat bentuk bulatan dan mula mencari barang yang hilang. Semakin lama, kedudukan bulatan mereka dikecilkan dari suatu kawasan ke kawasan yang lain sehingga barang yang hilang itu diperoleh semula. Menurut Khairul Harun (dlm Azizah Mohd Nor, 1979), Randai daripada segi makna bermaksud peristiwa yang dipandang sebagai perumpamaan atau ibarat, sedangkan tarian dalam Randai menjadi pelengkap atau daya penarik kepada kesenian tersebut. Kesenian Randai ini disertai dengan ucapan perpisahan sehingga Randai juga digolongkan sebagai teater tradisional rakyat Minangkabau. Persembahan Randai penuh dengan pembicaraan berandai-andai yang dihiasi dengan kiasankiasan, perumpamaan dan lain-lain termasuk seni pertuturan yang lahir secara spontan dalam bentuk cerita atau disebut 'kaba' dalam dialek Minangkabau (Abd. Samad Kechot, 2009).

Randai dalam tradisi Minangkabau turut dikenali dengan nama "Kaba" yang membawa pengertian cerita. Kaba kebiasaannya disebut dengan 'be-ka-ba', iaitu bercerita atau berdendang. Pada mulanya Kaba didendangkan oleh seorang penutur sahaja, kemudian berkembang dengan penambahan dua atau tiga orang penutur untuk suatu penceritaan. Penutur-penutur ini akan membuat lingkaran dalam bentuk bulatan dan bercerita secara bersahut-sahutan dan sambung menyambung lalu diakhiri dengan nyanyian yang dinyanyikan secara bersama-sama (Azizah Mohd Nor, 1979). Randai dipersembahkan secara berkeliling atau dalam lingkaran, dan jumlah pelakonnya tidak ditetapkan. Kesenian ini diperkenalkan pula dengan bentuk kesenian baharu iaitu komedi bangsawan. Memandangkan bentuk yang baharu ini sesuai dan dekat dengan bentuk kesenian yang sebelumnya, maka dengan mudah bentuk kesenian ini diterima dan berpadu untuk melahirkan suatu bentuk teater rakyat dalam bentuk Randai itu. Beberapa peristiwa dan tokoh daripada sesebuah cerita mulai divisualisasikan dan dipentaskan sehingga muncul lakonan dan penggunaan dialog dalam kesenian tersebut. Daripada proses perkembangan tersebut, muncul unsur-unsur dan ciri-ciri essensial yang baharu daripada bentuk kesenian Randai sebagai teater rakyat. Kewujudan kesenian ini bermula daripada perkembangan beberapa bentuk kesenian sehingga menjadi suatu bentuk kesenian baharu, iaitu Randai sebagai teater rakyat (Abd. Samad Kechot, 2009).

Penceritaan dalam Randai merupakan unsur penting dalam sesebuah persembahan Randai selain daripada gurindam. Salah satu contoh cerita yang sering dijadikan tunggak utama dalam persembahan Randai di Negeri Sembilan ialah 'Rangkayo Mudo'. Gurindam pula merupakan sejenis dendangan tradisional Melayu dalam bentuk pantun yang bermula daripada bahagian cerita dalam persembahan Randai. Fungsi gurindam ialah sebagai variasi menyampaikan cerita, menyatakan perubahan tempat, perubahan waktu, perubahan suasana dan menggerakkan cerita dalam persembahan Randai. Selain itu, gurindam juga berfungsi untuk menyampaikan bahagian cerita yang tidak dilakonkan dan didialogkan. Gurindam kadang-kadang diiringi muzik instrumen seperti bangsi dan saluang. Gurindam dalam persembahan Randai juga berperanan sebagai alat mengedit untuk meringkaskan cerita, memperkukuh plot, memberikan tekanan pada bahagian cerita yang penting atau menceritakan tokoh tanpa menampilkan orangnya (pemain) di hadapan penonton. Oleh yang demikian, gurindam dalam persembahan Randai berfungsi untuk menyampaikan cerita dalam bentuk deskriptif dan ilustratif, sedangkan cerita yang bersifat dramatik disampaikan melalui dialog dan lakonan. Persembahan Randai di Negeri Sembilan terdiri daripada dua jenis iaitu gurindam jenis sedih dan gurindam jenis gembira. Gurindam jenis sedih ialah dendangan yang sedih atau mendatangkan hiba sedangkan gurindam jenis gembira ialah dendangan yang memberikan kesan gembira. Terdapat gurindam yang menyerupai bentuk pantun 
yang mempunyai pembayang maksud 'sampiran' dan ada pula yang terikat dengan cerita. Pantun yang mempunyai pembayang maksud yang bebas ialah pantun yang sampirannya tidak berhubung dengan isi cerita. Pantun yang terikat dengan cerita pula ialah pantun yang mempunyai sampiran dan isi yang berkaitan dengan jalan cerita (Abd. Samad Kechot, 2009).

Tunjang kepada persembahan Randai juga bergantung kepada kemahiran tukang goreh. Tukang goreh merupakan ketua dalam persembahan Randai yang bertanggungjawab mengharmonikan suasana dalam persembahan. Apabila suasana persembahan menjadi hambar, maka tukang goreh harus bijak menangani situasi tersebut dengan mengubah gerak gelombang menjadi lebih dinamis dan agresif. Gerakan akan disesuaikan dengan irama gurindam yang dibawakan. Menurut Encik Saad Harun (dlm Abd. Samad Kechot, 2009) tukang goreh boleh memanjangkan dan memendekkan persembahan. Apabila penonton meminta agar suasana disemarakkan atau memendekkan gerak gelombang, maka tukang gorehlah menentukannya. Umumnya gerak gelombang akan seiring dengan permainan tepuk gelembung, tepuk paha dan tepuk tangan. Sebaik sahaja selesai persembahan, kesenian ini akan diakhiri dengan tepuk gelembung, tepuk paha, tepuk tangan dan juga tepuk dada. Kemudian, tukang goreh akan memberikan tanda kepada pemain untuk duduk dalam posisi tetap melingkar. Oleh sebab itu, seseorang yang dilantik sebagai tukang goreh harus tahu jalan cerita, mempunyai suara yang bagus dan lantang, menguasai gerakan, pola-pola pukulan gelombang, paha dan tangan.

Ringkasnya, kesenian Randai merupakan salah satu hasil kesenian tradisional rakyat Negeri Sembilan yang diwarisi daripada kesenian Minangkabau. Kesenian ini dapat dikategorikan sebagai teater rakyat yang di dalamnya mempunyai pelbagai bentuk kesenian tradisional yang lain iaitu tarian (gelombang), nyanyian (dendang/gurindam/pantun) dan seni peran (lakonan-dialog). Kesenian Randai dipersembahkan dalam kedudukan melingkar dan khalayak penonton bertepuk tangan sebaik sahaja sesebuah pantun dilagukan. Usia kesenian Randai ini tidak diketahui, namun kewujudannya seiring dengan migrasi orang Minangkabau yang berhijrah ke Negeri Sembilan pada abad kelima belas.

\section{Fungsi kesenian Randai}

Kesenian Randai memenuhi fungsi utamanya sebagai medium hiburan kepada masyarakat Perpatih. Sebagai medium hiburan, kesenian Randai dijadikan hiburan oleh masyarakat Perpatih setelah seharian bekerja, bertani membanting tulang sepanjang hari. Kesenian ini sering kali dipersembahkan setiap kali selepas menuai padi dan juga semasa pertandingan layang-layang. Selain itu, kesenian Randai turut dipersembahkan di dalam majlis perkahwinan, majlis kesyukuran dan majlis keramaian umum.

Kesenian Randai mempunyai fungsi yang lebih mendalam selain daripada fungsinya sebagai hiburan. Fungsi tersirat tersebut sebenarnya menggambarkan sistem nilai yang terdapat dalam sistem Adat Perpatih. Dalam konteks ini, nilai-nilai hidup bermuafakat jelas terlihat dalam struktur kesenian Randai. Persembahan Randai yang dimainkan dalam bentuk bulatan melambangkan kata sepakat dan bersatu hati dalam masyarakat khalayaknya. Seperti contoh pepatah 'bulat air kerana pembetung, bulat manusia kerana muafakat.

Ringkasnya, kesenian Randai ialah persembahan teater rakyat yang menghubungkan pelbagai unsur seperti unsur muzik, lakonan, cerita, dan tarian yang diselangi nyanyian berunsurkan lagu rakyat. Persembahannya diiringi dengan alat-alat muzik tradisional seperti caklempong, rebana, salung dan gong. Kesenian ini dipersembahkan dalam bentuk arena atau dalam gelanggang yang melambangkan satu keadaan bersatu padu dalam kalangan masyarakat 
Perpatih. Penari-penarinya terdiri daripada 12 orang yang melambangkan 12 suku yang terdapat di Negeri Sembilan.

Pada masa kini, kesenian Randai masih boleh dijejaki dan mempunyai peminatnya. Kesenian ini masih giat dipersembahkan terutamanya di daerah Lenggeng, kerana rata-rata daripada penduduknya terdiri daripada suku Minang. Hal ini dapat dibuktikan dengan kewujudan pelbagai kumpulan Randai yang giat dan bersungguh-sungguh menghidupkan kesenian ini seperti kumpulan Putrasari yang dibimbing oleh Encik Zainuddin Bujang, pelatih teater Randai Encik Mazdar Abd Aziz (Pak Pen) dan Encik Mawlid Zaenie yang sentiasa bekerjasama dengan pihak Jabatan Kebudayaan dan Kesenian Negeri Sembilan (JKKNNS) untuk melatih anak-anak muda daripada pelbagai institusi pengajian tinggi awam mahupun swasta malah melibatkan pelajarpelajar sekolah yang mempunyai minat untuk mempelajari kesenian ini. Sesuai dengan pengucapan adat "pusako nan bajaweh dan warih nan batolong" yang membawa maksud "pusaka dan waris yang memerlukan ahli warisnya" membuktikan bahawa kesenian Randai akan terus diwarisi secara turun-temurun daripada generasi kepada generasi berikutnya.

\section{Manifestasi budaya dalam kesenian Randai}

Kajian ini menumpukan persembahan kesenian Randai yang terdapat di mukim Lenggeng dalam daerah Seremban yang mempunyai keluasan 14,414.13 km persegi. Mukim Lenggeng merupakan mukim yang kelapan dalam daerah Seremban dengan jumlah penduduk 8305 orang. Masyarakat di sini bertutur dalam bahasa Minang dan bahasa Melayu. Kesenian Randai amat popular di mukim ini disebabkan masih ramai penutur yang mampu berbahasa Minang. Hal ini membawa kepada kesinambungan kepada pewarisan dan kebolehan dalam mempersembahkan kesenian tersebut.

Kajian ini menggunakan konsep etnomuzikologi untuk mengkaji hubungan muzik dengan lain-lain aspek kebudayaan dengan memberi tumpuan terhadap seni kata lagu dan hubungannya dengan aspek kebudayaan. Aspek kebudayaan yang dikaji ialah berhubung agama dan kepercayaan. Kepercayaan adalah yang meliputi penganutan agama dan keyakinan terhadap wujudnya kuasa-kuasa dan unsur-unsur ghaib serta kudus di sebalik alam fizikal. Dalam agama terdapat etika, moral, peraturan dan pembalasan baik dan buruk. Agama dan kepercayaan menjadi asas kepada pembentukan etos yakni nilai dan norma orang Melayu. Oleh yang demikian agama dan kepercayaan itu mempunyai kedudukan yang paling penting dalam kebudayaan (Syed Nurul Akla Syed Abdullah, 2001).

Dalam membincangkan aspek ini, pengkaji telah menemukan dua persoalan, iaitu konsep ibadah dalam Islam dan kepercayaan kepada Rukun Iman yang terungkap menerusi lirik-lirik lagu. Penting untuk dinyatakan bahawa konsep ibadah dan kepercayaan kepada Rukun Iman merupakan dua perkara asas yang perlu bahkan wajib dipercayai dan ditaati oleh setiap individu yang beragama Islam. Ibadah secara umum ialah bakti dan kepatuhan manusia kepada Allah SWT, sesuai dengan tuntutan akidah dan tauhid. Ibadah merupakan perkataan Arab yang bermaksud pengabdian, penyembahan, ketaatan, menghinakan atau merendahkan diri dan doa, yakni perbuatan yang dilakukan sebagai usaha menghubungkan dan mendekatkan diri kepada Allah SWT sebagai tuhan yang disembah (Abdul Azis Dahlan, 1996). Dalam konteks ini, ibadah merupakan khidmat kepada Tuhan yang telah diperluaskan maksudnya dalam kerangka Islam sebagai mentaati segala perintah Allah SWT, berusaha menjauhi larangan-Nya serta mengamalkan segala yang disuruh-Nya.

Ibadah dalam Islam dapat dibahagikan kepada dua bahagian yakni ibadah khusus dan ibadah yang umum. Ibadah yang khusus ini merupakan penelitian terhadap kepatuhan dan 
ketundukan manusia kepada hukum-hakam yang termaktub dalam Fardu Ain. Sementara itu pula, ibadah yang umum ialah kegiatan Muslim dalam bidang yang berkaitan dengan urusan kekeluargaan, masyarakat dan negara melalui keikhlasan hati yang didasarkan kepada kebaikan dan kebenaran (Imam al-Ghazali, 2006). Dengan kata lain, ibadah ialah semua aktiviti manusia yang merujuk kepada keredaan Allah SWT yang dinilai dari sudut niat seseorang. Oleh yang demikian, ibadah merangkumi hubungan manusia dengan pencipta-Nya (habl min Allah) dan hubungan manusia dengan manusia ( habl min al-nas). Hal ini kerana adanya panduan yang erat antara nilai akidah dan ibadat dalam diri seseorang Muslim itu dalam proses perkembangan kehidupan dengan yang Maha Pencipta. Proses ibadah ini sebenarnya dapat membentuk kekuatan manusia dari sudut emosi dan spiritual yang menggalurkan ganjaran yang baik bukan sekadar di dunia tetapi di akhirat.

Ayat tersebut menjelaskan kepentingan ibadah dari sudut hubungan manusia dengan Allah SWT, hubungan manusia dengan manusia dan hubungan manusia dengan makhluk lainnya. Hal ini memperlihatkan hubungan antara akidah dan tauhid yang menjadi tunjang seorang Muslim bagi melaksanakan kepatuhannya terhadap segala suruhan Allah SWT dan meninggalkan segala larangan-Nya untuk mencapai tahap keimanan yang tinggi. Berdasarkan huraian di atas, pengkaji telah menemukan bait-bait lagu yang condong kepada persoalan ibadah menerusi Lagu Hujung Tanah seperti berikut:

Tiga hari bulan rejangnya harimau, Harimau mati turun ke baruh, Mati ditikam orang balu; Tuntut apa ilmu bersuci, Seperti fardu ke atas ku.

Empat hari bulan rejangnya kucing, Kucing melompat di atas tilam, Turun ke kebun memakan kepiat; Serge ternanti akan Islam, Di situlah terhimpun sekalian jeriat.

Sepuluh hari bulan rejangnya naga, Naga tasik cahaya tujuh, Menghambat ikan berkawan-kawan;

Kalua mengetahui martabat tujuh Mengetahuilah sifat hambanya Tuhan.

Lima belas hari bulan rejangnya ikan, Ia kan ada di dalam kolam, Mati ditikam dengan galah; Segera ternanti akan Islam, Itulah nikmat diberi Allah.

Setiap umat Islam wajib menunaikan ibadah fardu yakni disebut sebagai solat fardu, dilakukan lima kali sehari. Dalam konteks ini, ia merupakan ibadah wajib ditunaikan oleh umat Islam dalam menjaga hubungan dengan pencipta-Nya. Solat merupakan makanan hati yang 
membentuk keperibadian akhlak setiap individu yang mengerjakannya. Solat juga merupakan salah satu cara bagi memantapkan keimanan yang secara langsung meningkatkan ketakwaan individu Muslim selain merupakan tiang agama dan penghulu segala ibadat. Hal ini sepertimana Firman Allah SWT yang bermaksud:

"Kemudian apabila kamu telah selesai mengerjakan solat, maka hendaklah kamu menyebut dan mengingati Allah SWT semasa kamu berdiri atau duduk dan semasa kamu berbaring. Kemudian apabila kamu telah merasa tenteram (berada dalam keadaan aman) maka dirikanlah solat itu (dengan sempurna dan biasa). Sesungguhnya solat itu adalah satu ketetapan yang diwajibkan atas orang-orang yang beriman, yang tertentu waktunya" (Surah al-Nissa, ayat 130).

Persoalan kedua yang digariskan dalam lirik lagu dalam kesenian Randai adalah mengenai kepercayaan kepada qada dan qadar yakni perkara terakhir dalam prinsip Rukun Iman. Sebagai individu Islam, adalah wajib bagi mereka untuk mempercayai dan mentaati perkara-perkara yang terkandung dalam Rukun Iman. Secara umumnya, perkataan qada merupakan kepastian dan perkataan qadar merupakan ketentuan. Kedua-duanya merupakan ilmu pengetahuan Allah SWT yang azali dan kekal terhadap setiap perkara dan alam yang hendak diciptakan-Nya dan juga terhadap makhluk serta kejadian (Haron Din, 1997).

Oleh yang demikian, kepercayaan qada dan qadar Allah SWT ialah keyakinan setiap Muslim bahawa apa sahaja yang terjadi kepada diri seseorang, sememangnya telah ditakdirkan oleh-Nya. Untuk itu, setiap Muslim seharusnya wajib meyakini bahawa adanya ketentuan sebab dan akibat yang telah dilakukan Allah SWT yang akan membawa kepada kebaikan serta ada ketentuan sebab dan akibat yang akan membawa kepada keburukan. Sehubungan itu, setiap Muslim perlu yakin bahawa Allah SWT merupakan sebaik-baik perancang dan pelaksana terhadap nasib manusia di dunia dan di akhirat untuk membina sikap positif dan dinamik dalam mengharungi cabaran dan perjuangan hidup di dunia yang memerlukan usaha dan harapan hanya kepada kurniaan Allah SWT juga. Dalam konteks ini, kepercayaan qada dan qadar Allah SWT dipertalikan dengan konsep reda yang seharusnya dipasakkan dalam diri setiap Muslim bagi menggambarkan kekuatan akidah dan kejiwaannya (Haron Din, 1997).

Persoalan berhubung kepercayaan kepada qada dan qadar ini dapat dilihat menerusi Lagu Cantik Manis dalam kesenian Randai seperti berikut:

Apa direndang di kuali,

Padi Si Radin kuku balam;

Jangan ditumpang untuk kami,

Biduk tirih menanti karam.

Aur serumpun di atas gunung,

Ambil setulang sebelabas;

Jauh tampak dekat terlindung,

Di mana kasihkan berlepas.

Tidaklah dapat sihendak padi,

Dedak jua ditumbuk luluh;

Tidak dapat si kehendak hati, 
Kehendak Allah jua yang sungguh.

Baris lagu berkenaan menjelaskan bahawa apa sahaja suratan takdir yang ditentukan olehNya, hendaklah diterima dengan reda dan percaya akan kebaikan atau hikmah yang ada di sebalik setiap yang tersurat. Dalam konteks ini, konsep reda menjurus kepada menerima peraturan (hukum) Allah SWT yang dibebankan kepada manusia atau reda menerima ketentuan tuhan tentang nasib yang menimpa diri. Hal ini memperlihatkan keutuhan yang padu mengenai kepercayaan kepada qada dan qadar dalam diri masyarakat pendukung. Ia rata-ratanya menunjukkan ketegasan dan saranan masyarakat akan peri pentingnya mempercayai dan mentaati hal sedemikian yang mampu memantapkan pegangan akidah di samping membentuk keperibadian Muslim yang unggul. Menurut Imam al-Ghazali (2006), terdapat beberapa kebaikan yang diperoleh daripada kepercayaan kepada qada dan qadar yakni:

i. Hidup akan tenteram, tidak berasa takut kerana sudah mengetahui bahawa takdir Allah itu pasti akan berlaku pada dirinya.

ii. Tidak akan merasa sedih atas segala keinginannya yang tidak tercapai sebab mengetahui perkara itu tidak ditakdirkan Allah untuk diperolehnya.

iii. Tidak akan berasa terlalu gembira atas segala yang diterimanya sama ada berbentuk harta, anak mahupun kekuasaan kerana itu merupakan takdir Allah SWT untuk dirinya, ia hanya bersyukur dengan kurniaan Allah SWT tersebut.

iv. Mengerjakan sesuatu yang dibolehkan atau diperintahkan kepadanya dan meninggalkan segala yang dilarang oleh Allah SWT dengan hati dan perasaan yang tenang.

v. Mengetahui segala kejadian dan peristiwa itu terjadi menurut ketentuan Allah SWT, maka ia akan mencari jalan yang boleh membawanya ke arah kebaikan dan menghindarkan diri daripada bahaya dan kerugian.

Secara keseluruhannya, aspek agama dan kepercayaan ini tergambar menerusi bait-bait lagu sepertimana yang telah dijelaskan. Hal ini mendukung prinsip-prinsip asas dalam pembentukan akidah masyarakat Melayu amnya dan masyarakat Perpatih khasnya yang mempercayai dan menjadikan ia sebagai panduan dalam meneruskan kelangsungan hidup. Saranan dan ketegasan dalam lirik-lirik lagu tersebut memberikan cerminan mengenai pegangan dan ideologi masyarakat pendukung tentang keseluruhan aspek budaya yang melatari kehidupannya. Dalam konteks ini, agama Islam dan kepercayaan terhadap kebenarannya merupakan ideologi yang mencakup keseluruhan aspek kebudayaan yang lain. Hal ini sepertimana yang dinyatakan oleh Mohamed Anwar Omar Din (2007), yakni agama dan kepercayaan mempunyai kedudukan yang paling penting dalam kebudayaan. Ia menjadi perkara pokok yang melahirkan etos yakni nilai dan norma orang Melayu amnya, masyarakat Perpatih khasnya.

\section{Kesimpulan}

Kesenian Randai di Negeri Sembilan sememangnya mempunyai keunikannya yang tersendiri. Elemen-elemen budaya yang terkandung dalam lirik-lirik lagunya sarat dengan unsur nasihat dan peringatan yang halus untuk dihayati dan dijadikan teladan oleh masyarakat pendukung. 
Penerapan berhubung aspek keagamaan merupakan salah satu perkara yang sangat dititik beratkan dalam kesenian ini meskipun ia hadir dalam bentuk hiburan. Kelestarian kesenian ini perlu dipandang serius oleh semua pihak, lebih-lebih lagi masyarakat Perpatih kerana ia merupakan khazanah intelektual yang memperlihatkan ketinggian pemikir masyarakat yang melahirkannya.

\section{Rujukan}

Abd. Samad Idris. (1974). Kemurnian dalam Adat Perpatih. Seminar Persejarahan dan Adat Perpatih, Seremban, Pustaka Asas Negeri.

Abd. Samad Kechot. (2009). Laporan kajian Randai warisan masyarakat Minang Negeri Sembilan: meneroka perkembangan dan taburannya. Jurnal Melayu, 4, 161-172.

Abdul Azis Dahlan. (1996). Ensiklopedia Islam. Jakarta, Islamic Publications.

Arifini Netrirosa. (2010). Kompleksiti persembahan Randai dalam kehidupan masyarakat Minangkabau di Sumatera Barat (Tesis Sarjana). Pusat Pengajian Seni, Universiti Sains Malaysia.

Azizah Mohd Nor. (1979). Permainan tradisional Randai di Lenggeng, Negeri Sembilan (Latihan Ilmiah). Fakulti Sains Sosial dan Kemanusiaan, Universiti Kebangsaan Malaysia.

Hamzah Jusoh, Habibah Ahmad, Amirah Buang, \& Ari Kurnia. (2001). Melaka sebagai pintu masuk pelancongan Sumatera: Perkembangan semasa dan cabaran era global. GeografiaMalaysia Journal of Society and Space, 7(5), 2-13.

Haron Din. (1997). Manusia dan Islam. Kuala Lumpur, Dewan Bahasa dan Pustaka.

Imam al-Ghazali. (2006). Ihya Ulumuddin pengajaran bagi orang-orang mukmin. Kuala Lumpur, Darul Fajar.

Khoo Kay Kim (1990). Adat Perpatih dan pembangunan negara. Dlm. Norazit Selat (Ed.), Negeri Sembilan dahulu dan sekarang (hlm. 43-55). Kuala Lumpur, United Selangor Press.

Midawati, \& Amirah Buang. (2015). Wanita Perpatih dan keusahawanan di Negeri Sembilan: suatu tinjauan geografi sejarah. Geografia-Malaysia Journal of Society and Space, 11(2), 128-139.

Mohd Dahlan Mansoer. (1990). Negeri Sembilan: sejarah awal dan sistem politiknya. Dlm. Norazit Selat (Ed.), Negeri Sembilan dahulu dan sekarang (hlm. 3-20). Kuala Lumpur, United Selangor Press.

Mohamed Anwar Omar Din. (2007). Asas kebudayaan dan kesenian Melayu. Bangi, Penerbit Universiti Kebangsaan Malaysia.

Nelmawarni Bungo, \& Nordin Hussin. (2011). Merantau ke Kuala Lumpur: Tradisi merantau dan berdagang masyarakat Minang. Geografia-Malaysia Journal of Society and Space, 7(5), 116-131.

Syed Nurul Akla Syed Abdullah. (2001). Faktor leksis dan budaya dalam terjemahan ArabMelayu: Satu analisis karya rihlah (Tesis Sarjana). Fakulti Bahasa Moden dan Komunikasi, Universiti Putra Malaysia. 